\title{
Enhancing the Digital Backchannel Backstage on the Basis of a Formative User Study
}

\author{
http://dx.doi.org/10.3991/ijet.v7i1.1898 \\ Alexander Pohl ${ }^{1}$, Vera Gehlen-Baum ${ }^{2}$ and François Bry ${ }^{1}$ \\ ${ }^{1}$ Institute for Informatics, University of Munich, Munich, Germany \\ ${ }^{2}$ Educational Technology, Saarland University, Saarbrücken, Germany
}

\begin{abstract}
Contemporary higher education with its large audiences suffers from passivity of students. Enhancing the classroom with a digital backchannel can contribute to establishing and fostering active participation of and collaboration among students in the lecture. Therefore, we conceived the digital backchannel Backstage specifically tailored for the use in large classes. At an early phase of development we tested its core functionalities in a smallscale user study. The aim of the study was to gain first impressions of its adoption, and also to form a basis for further steps in the conception of Backstage. Regarding adoption we particularly focused on how Backstage influences the participants' questioning behavior, a salient aspect in learning. We observed that during the study much more questions were uttered on Backstage than being asked without backchannel support. Regarding the further development of Backstage we capitalized on the participants' usability feedback. The key of the refinement is the integration of presentation slides in Backstage, which leads to an interesting reconsideration of the user interactions of Backstage.
\end{abstract}

This article is a reworked and extended version of the authors' submission for the International Conference ICL 2011.

Index Terms-Extended Classroom, Digital Backchannel, Questioning.

\section{INTRODUCTION}

Maybe everyone in her academic life has attended some instructor-centered lectures with large and anonymous audiences and only few students actively partaking. Although findings suggest that active participation contributes to better learning (e.g. [1,2]), large class lectures do not provide much space for an actively participating and collaborating audience. Certainly, social mediation, i.e., the feasibility of social interaction between a teacher and her audience as well as among the students, is a limiting factor: the larger the class, the fewer social interaction takes place. In groups with more than 30 members, a manager is needed to facilitate discourse. In many cases, the teacher plays this role [3].

Discourse between persons often follows certain triadic communication structures or patterns. For example, a discourse pattern frequently observed in classrooms is the IRE (Initiation, Response, and Evaluation) pattern: the teacher initiates discourse by posing a question; a student responds to that question that is finally evaluated by the teacher. Besides evaluation, the discourse can also follow the IRF (Initiation, Response, and Follow up) pattern: the teacher may follow up on student's response with a further comment [3].

Yet, in such a discourse usually only few persons, i.e. the teacher and a few students, are involved. The large part of the audience basically remains passive. According to the constructivist's perspective, however, learners construct their own knowledge and understanding, which requires active participation in the learning process [4]. Furthermore, educational scientists have developed the theory of communities of learners, according to which learning is not understood as a transfer of knowledge between experts, nor an acquisition of experts' knowledge by novices, but rather as a transformation of the learner's participation in the learning process [5].

One way to increase active participation of and social interaction among students may be to employ textual computer-mediated communication in the classroom, since "Text-only CMD [Computer Mediated Discourse] is a surprisingly effective way to 'do' interactional work [...]" [6]. Besides, CMD is effective in encouraging students to participate in the discourse. For example, in the field of second language learning, it has been observed how CMD is adopted by students for their learning and how it affects their participation [7]. It is reported on the observation that every student participated in CMD, including those students who are shy and more selfconscious about the mistakes they make than other students. Furthermore, the balanced nature of CMD has been highlighted: students that dominate classroom discourse, e.g. by answering every question posed by the teacher, do not dominate CMD. Every student gets a chance to speak without being interrupted.

To support collaboration and active participation in the lecture it has been proposed to enhance the classroom with digital backchannels, i.e., computer-mediated synchronous (textual) communication tools, making non-disruptive information exchange among the audience during the lecture possible. Providing a social environment in which questions can be raised during the lecture can be a major benefit of backchannels, especially in large class lectures. However, we contend that current digital backchannels do not sufficiently meet the conditions and requirements imposed by large class lectures.

\section{A. Using Backstage in Large Classes}

We conceived the digital backchannel Backstage, which provides a rich set of interactions specifically tailored for the use in large lecture classes. Its basic functionalities comprise fast information exchange, various kinds of feedback dedicated to both the student 
and the lecturer, and incentives to partake. In the remainder of this section, we provide a short overview of Backstage. For a more detailed description the interested reader is referred to $[8,9]$.

By means of a microblog, students may exchange ideas and comments through short messages, comprising only a few words. The most prominent example of a microblog is Twitter $^{1}$, in which messages comprise a maximum of 140 characters. Microblogs allow messages to be written and read quickly, and hence are well suited for the use as digital backchannels in large class lectures. Backstage provides different modes of communication: messages can be visible either to the public or to certain users only (private communication). Besides, the author's username may be shown along with each of her message or be hidden (anonymous communication). Indeed, one can argue for or against the usefulness of all these modes of inter-personal communication. For example, anonymous communication certainly lowers the barrier to partake, especially during the first turns at the beginning of a semester, but may likewise simplify the dissemination of offending messages. We think that whether certain modes of communication should be available largely depends on the compilation of the audience and the topic of the lecture. Thus, Backstage is highly customizable by the lecturer, meaning that the lecturer, even during lecturing, can easily change the availability of the different modes of communication provided by Backstage.

Students may assign messages to certain predefined categories, e.g. "Question" or "Lecturing Pace". According to these categories, messages can be filtered out, aggregated and be displayed at the lecturer's dashboard. This provides her with a concise and simple topic-related overview of the backchannel discourse. Thus, categories can be used by students to give immediate feedback to the lecturer related to contents (e.g. "Question", "Remark") or to lecturing style (e.g. "Lecturing Pace").

Messages can furthermore be rated by students to assess the relevance of a message for the lecture. This is provided on Backstage by means of a simple rating scheme allowing students to quickly express approval or rejection of a message. Rating in the context of Backstage serves two important purposes. First, it makes possible to determine a ranking of the top $\mathrm{k}$ messages that can be displayed at the lecturer's dashboard. Combined with the topic-related aggregation of messages described in the previous paragraph the lecturer obtains a very concise, yet meaningful overview of the backchannel discourse. Second, rating provides feedback to students given by their peers. This feedback can furthermore be accumulated to form a kind of status for a student. The better her messages are rated the higher the status she gains.

To promote active participation the lecturer can conduct short quizzes, reminiscent to Audience Response Systems ${ }^{2}$ (ARS; e.g. [10-12]) via Backstage. A student's concentration drastically declines after 20 minutes of continuous lecture [13]. Quizzes allow the instructor to break up the lecture into smaller sections and to assess factual knowledge and students' retention. In addition to

\footnotetext{
${ }^{1}$ http://www.twitter.com

2 Audience Response Systems are also referred to as Student Response Systems, Personal Response Systems, and Clicker Systems, among others.
}

fostering active participation, quizzes provide feedback about the student's performance relative to their peers. When the lecturer starts a quiz, the students' dashboards display a multiple-choice item. The students' responses are displayed and updated in real-time at the lecturer's dashboard. As soon as the lecturer closes the voting phase, the responses are aggregated and displayed at both the lecturer's and the students' dashboards for further review.

\section{B. Usability-A Tradeoff between Economy of Effort and Learning}

In [14], usability is defined as "a quality attribute that assesses how easy user interfaces are to use", and is operationalized by five variables. While some of these, e.g. the number and severity of errors the user makes (errors) or the time necessary to rebuild the knowledge acquired after some time of not using the system (memorability), are important to consider for all kind of software, the remaining three variables-learnability, efficiency, and satisfaction-are of particular importance for computer-based learning environments.

In most cases it is rational to simplify user interactions by means of a clear and concise user interface (learnability) that enables users to quickly accomplish their tasks (efficiency). However, the resulting economy of effort, especially when considering user interfaces of applications for learning, might not always be the best way to improve learning processes and results. Studies on expertise have shown that many activities are quickly learned to an extent sufficient for daily life. In order to become an expert, however, it is necessary to perpetually reflect, and possibly deviate from, the activities as being taught [15]. Therefore it could be fruitful to provide user interactions that initiate some cognitive activity in the learning environment.

Learning environments often adopt user interactions from well-known applications such as Facebook ${ }^{3}$ or Twitter which are familiar to most learners. This allows users to quickly grasp the way to interact with the application (learnability) and to quickly accomplish the tasks without much need for settling in. However, besides mere usability, further-educational-design parameters need to be taken into account in order to ease interactions as well as provide for occasions in which the user can reflect on her interactions. Similar to Piaget's "Conceptual Change" [16] that can be observed in children being stretched to their limits due to insufficient mental models of the world, adult learners should be stretched to their limits when carrying out learning tasks in a sub-optimal manner. Likewise, they should be provided with instructions supporting them in optimizing their learning. In Computer Supported Collaborative Learning (CSCL) this is frequently achieved by the provision of collaboration scripts: learners obtain roles according to which the tasks and the orders in which to carry out these tasks are specified. Several studies could substantiate the superiority of this approach compared to respective controls (e.g. [17-19]).

Undoubtedly, usability is an essential aspect of the design of learning platforms. However, it might prove reasonable-with sound judgement - to attach more importance on educational claims (e.g. the conveyance of

\footnotetext{
${ }^{3}$ http://www.facebook.com
} 
competencies in questioning) rather than on mere usability principles.

\section{Asking the Right Kinds of Questions to Improve Understanding}

In several articles (e.g. [20,21]) it has been argued that questioning is an important strategy to elaborate new knowledge. Unfortunately, students often find it difficult to ask for help and further explanation [22]. This is not surprising, considering that formulating questions already requires some understanding of, and former knowledge about, the topic (e.g. [20]). Questioning is thus subject of various fields of research. For example, reciprocal teaching [23] and script research (e.g. [24,25]) deal with questioning or at least highlights its importance [26].

Not only the quantity, but also the quality, of questions is important for learning [25]. In ibid. a distinction is made between three kinds of questions: factual, comprehension, and integration questions. The Table I summarizes the descriptions of questions and their distinctions regarding knowledge.

TABLE I.

KINDS OF QUESTIONS (FROM [25], P. 350, WITH MINOR ADAPTATIONS).

\begin{tabular}{|l|l|}
\hline \multicolumn{1}{|c|}{ Question } & \multicolumn{1}{c|}{ Description } \\
\hline Factual & $\begin{array}{l}\text { Asks for recall of facts or other information } \\
\text { explicitly covered in the lesson. } \\
\text { Encompasses knowledge restating: Simple } \\
\text { statements of fact or information gleaned } \\
\text { directly from the lesson or prior knowledge. } \\
\text { Asks for a process or term to be described or } \\
\text { defined. } \\
\text { Encompasses knowledge assimilation: } \\
\text { Definitions, descriptions, and other material } \\
\text { paraphrased in student's own words. }\end{array}$ \\
$\begin{array}{l}\text { Goes beyond what was explicitly stated in the } \\
\text { lesson, connects two ideas together, or asks } \\
\text { for an explanation, inference, justification, } \\
\text { etc. } \\
\text { Encompasses knowledge integration: Makes } \\
\text { new connections or goes beyond what was } \\
\text { provided in the lesson - explanations, } \\
\text { inferences, relationships between ideas, } \\
\text { justifications, statements, linking session } \\
\text { content to material from outside the lesson } \\
\text { (prior knowledge and personal experience). }\end{array}$ \\
\hline
\end{tabular}

In order to achieve better learning results, it is especially important to formulate integration questions as these are connected to a deeper elaboration, though it is quite uncommon that integration questions are raised without being fostered by appropriate guidance. These were the findings of the study presented in [25], were it has been shown that integration questions could be trained and lead to a "more complex knowledge construction" (p. 338).

\section{Research Question}

We tested the Backstage prototype in a preliminary user study at an early stage of development. The aim of the study was to gain first impressions of the usability of Backstage and its adoption for questioning. Thus, we focused on the following questions. (1) What are the participants' impressions of the usability of Backstage? (2) What kinds of questions were asked on Backstage in comparison to traditionally held presentations without any backchannel support? (3) How do these questions correlate with the participants' attitudes towards asking questions on Backstage?

\section{METHOD}

\section{A. Participants and Design}

Nineteen participants from different subjects (mainly Educational Science and Informatics but also Psychology and German as foreign language) participated in this study. The mean age of the participants was $\mathrm{M}=26.32$ $(\mathrm{SD}=3.33)$. Five $(26.32 \%)$ participants were female and fourteen $(73.68 \%)$ were male. Since few can be said about students' prior knowledge in large lectures, we decided to omit a pretest for this preliminary study and thus chose an experimental design with one control group. The participants were picked randomly from the different fields of study. Every participant in the experimental group was assigned a working place equipped with a PC, resembling traditional computer-based learning environments. Although unnecessary, each participant of the control group was also assigned a PC working place.

To assure that the prototypical implementation of Backstage was able to cope with the amount of data that was to be processed we subdivided the experimental group (fourteen participants) into three subgroups with five and four participants, respectively. For the control group, we used the equal group size of five participants in order to ensure the participants weren't inhibited by a larger group size.

\section{B. The Learning Environment}

A 30-minutes presentation was held in front of each group in a room with PC workplaces. The presentation was about two educational subjects which were presented for ten to fifteen minutes each. The first talk was about the notion of transfer-the definition, the reasons why it occasionally fails to take place and the ways to foster it. The second part was about the research on expertise- the definition and a short overview of this field. We tried to eliminate additional talk in the classroom. The participants of the control group listened to the presentation in a traditional way and thus were invited to raise hands.

Prior to each trial, every participant in the experimental group was already logged into Backstage using pseudonyms. The experimental group could only use certain features of Backstage. As the study was conducted at an early stage of development, several features were not completely implemented or unstable. The participants were informed about the state of implementation and the features that could be used.

The Figure 1 shows the layout of the students' dashboards. The microblog communication capabilities as described in Section I.A were completely functioning and available. The participants could also rate messages, although the rating scores of the messages were not aggregated and rendered along with each message. The participants could also assign messages to categories that were already aggregated properly and were rudimentarily displayed at the presenter's dashboard. The top-k ranking of messages was also not available but the presenter strived to respond to the questions that were raised on the backchannel. The quiz module was basically available, 


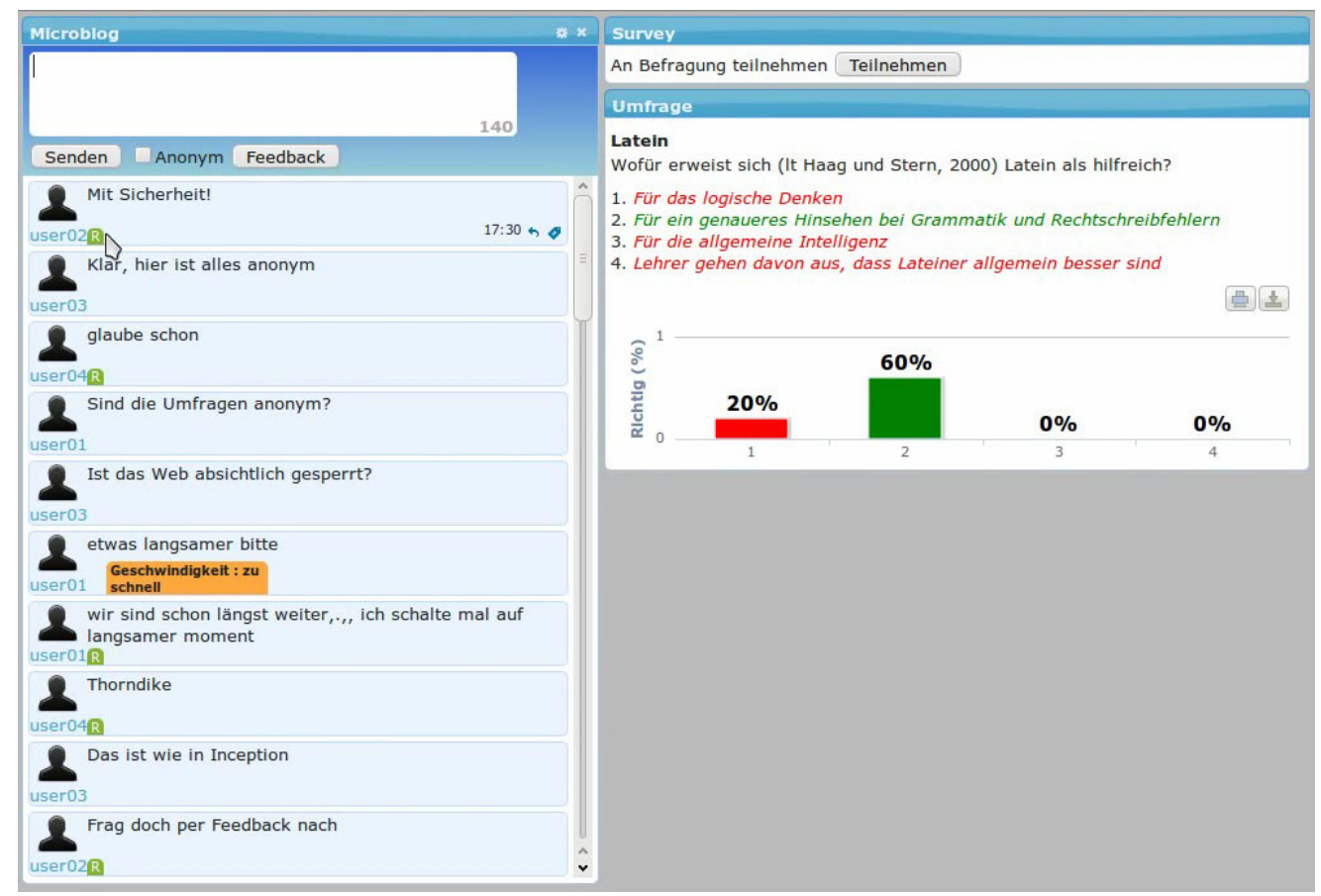

Figure 1. A participant's dashboard on Backstage. The picture shows the microblog editor and timeline (left) and the results of a quiz that has just been conducted (right). The dashboard shown is in German, since the user study was conducted in German.

although the rendering of quiz results was still in need for improvements.

\section{Instruments and Dependent Variables}

The dependent variables were (1) usability, (2) the participants' attitudes towards asking questions, and (3) the number and kinds of questions asked during the presentation. The first two variables were mainly measured by questionnaire items and by analysis of the backchannel communication.

We tested the usability with fourteen multiple choice questions (Likert scale ${ }^{4}$ from 1 to 6 ) and three open items. Since the participants were using Backstage for the first time, we considered more important to measure the time needed to get acquainted with the application, than other usability aspects, e.g. the number of errors the participants made. Thus, the learnability was measured by the time needed to get acquainted with Backstage and usability was measured by multiple-choice questions like "The application's user interface is clear and concise". The reliability of the usability questions were measured using Cronbach's $\alpha$ [27] that yields $\alpha=0.91$. In addition, the three open items were meant to give a deeper insight in what the participants liked or missed. The answers were sighted by two coders and certain categories like "questions to the presenter" were counted. Cohen's Kappa, by which the consensus between the two coders is measured [28], yields $\kappa=0.92$.

The attitude towards questions was measured with seven multiple choice questions like "I felt unsure when raising a question". The reliability yields $\alpha=0.77$.

The backchannel communication was exported to log files and the statements of the control group were

\footnotetext{
${ }^{4}$ The linguistic grades corresponding to the numeric grades 1 to 6 are: "strongly disagree" (1), "disagree"," tend to disagree", "tend to agree", "agree", and "strongly agree" (6).
}

transcribed accordingly. The statements were classified twice by distinct coders into "question", "response to question", and "feedback to the presenter". Since no other kinds of statements ended with questions marks, questions could be easily identified. A response to a question could be determined by its adjacency to the respective question or by context. Feedback to the presenter could be extracted in a similar way. In a second step, statements belonging to "question" were further subdivided according to their content into the classes given in the Table I $(\kappa=0.74)$.

Since the control group was not to answer questions regarding the usability of the application, we provided a similar questionnaire that focused on questioning. The outcomes of this questionnaire, however, are not presented in this article which focuses on the analysis of the process data.

\section{Procedure}

We conducted each trial during a 30-minutes presentation. The participants were assigned to the prepared places. For the control group, the places were additionally equipped with pen and paper and for the experimental group the login to Backstage had already been accomplished. The experimental group was provided with a brief introduction to Backstage and how to use the different functions. Furthermore, both experimental and control group were provided with a short summary about the outline of the study. The control group was particularly instructed to raise hands in order to pose a question during the presentation. The presentation was subdivided into two parts - the first part was about transfer, the second about expertise. After each section both groups were invited to raise questions. Immediately after the presentations, which were held comparably in contents and style, the participants were asked to fill out a questionnaire. 


\section{E. Statistical Analysis}

Due to the small group sizes we decided to forgo inductive statistical analysis and to restrict ourselves to descriptive analysis. However, in most cases the heterogeneous t-tests (not reported on in this paper) reveal significant differences between traditional presentations and presentations with Backstage running.

\section{RESULTS}

\section{A. Usability}

The mean $\mathrm{M}=4.42$ ( $\mathrm{SD}=0.78)$ on usability we measured is between "tend to agree" and "agree", thereby indicating that the participants found it easy and intuitive to work with Backstage: every participant posted at least one message on the backchannel during the presentation. Also, the participants' comments point in this direction. Notably, the time the participants stated to be necessary in order to get acquainted with Backstage highly varied. While the average was $\mathrm{M}=8.79(\mathrm{SD}=8.34)$ minutes, the minimum time stated was one minute and the maximum was 30 minutes.

By means of the open items we could figure out that the participants appreciated the possibility to directly send feedback to the presenter (mentioned eight times). The process data showed that the experimental groups gave feedback to the presenter more often than the control group $(M=5.43)$ which gave only short feedback, e.g. "ok" for acknowledging $(\mathrm{M}=0.40)$.

Also, Backstage's quiz functionality to assess current knowledge was appreciated by the participants of the experimental groups (mentioned five times).

However, they missed the easy-to-use communication known from other communication tools. Similar statements were made regarding the lack of presentations slides integrated in Backstage (mentioned twice). Three participants also noted the risk of getting distracted by the use of Backstage.

\section{B. Questions}

With Backstage the participants gave approximately nine times more remarks during the presentation than without the backchannel (Figure 2A).

Among the messages on the backchannel, only a small fraction was off-topic $(\mathrm{M}=2.5, \mathrm{SD}=2.82)$. $\mathrm{A}$ considerable amount of the messages were feedback $(\mathrm{M}=5.42, \mathrm{SD}=5.57)$. The largest part was questions (Figure 2A).

Participants of the experimental groups raised questions more frequently than of the control group. This is also reflected by the positive attitude towards asking questions on Backstage $(\mathrm{M}=4.56 ; \mathrm{SD}=.87)$. While few questions are about using Backstage, the large part of questions refer to the presentation contents. The questions of participants of the control group did not refer to the use of Backstage, but to the presentation's content only. The distribution of questions regarding the classification of questions as given in the Table I is illustrated in the Figure 2B.

\section{DISCUSSION}

Since this article reports on a preliminary study mainly focusing on first impressions of the usability of Backstage, only few statements can be made regarding the usefulness
A)

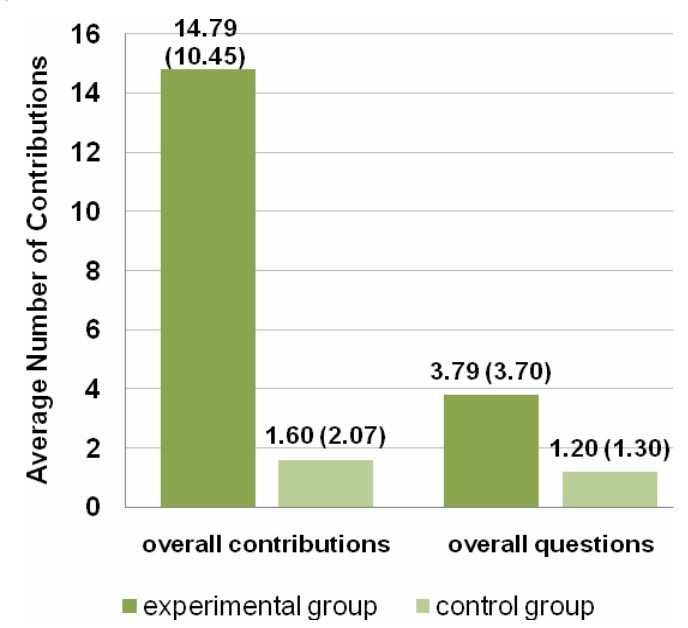

B)

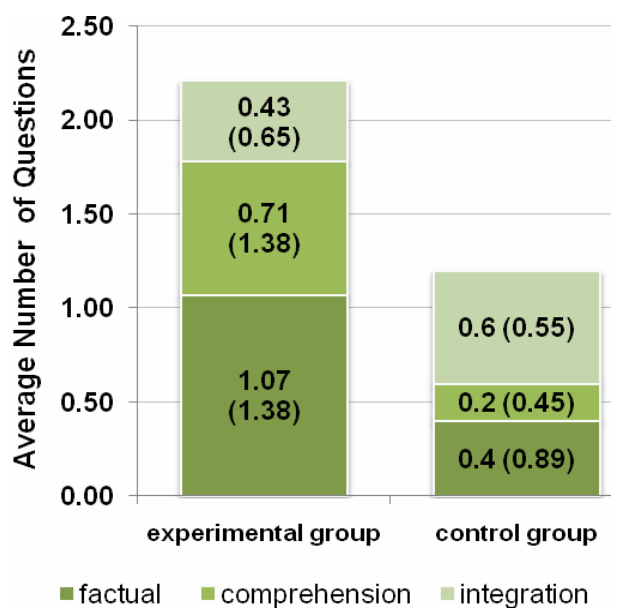

Figure 2. A) A participant's average number of contributions and questions, in particular. The numbers in brackets indicate the respective standard variances. B) A participant's average number of questions split in the kinds described in the Table I. The numbers in brackets indicate the respective standard variances.

of Backstage from an educational point of view. However, further studies to investigate the educational usefulness of Backstage are currently in the planning process.

\section{A. Usability}

The average time of nine minutes needed to get acquainted with Backstage is rather short, which can be attributed to the similarity to well-known platforms such as Twitter. However, the variability around the average could be a ramification of the participants' different notions of "becoming acquainted with Backstage", their backgrounds, or their levels of experience with new media. For clarification, however, further investigation is necessary.

Although the analysis of the questionnaires suggests that the participants liked working with Backstage, in the open items, the usability has been remarked to be in need of improvements. Keeping in mind that on Backstage the interaction design aims at triggering reflective thinking of users, this remark did not come up unexpectedly. Furthermore, the responds to the multiple choice questions suggest that most participants did not find the deficiencies too disturbing. The observation that every participant 
posted at least one message during the presentation indicates that Backstage is convenient to use and positively influences participation.

Whether learners are content with such a "rectified" user interaction design (satisfaction) or reject them, but at the same time achieve better learning outcomes, is an essential aspect that needs to be carefully considered. The learner may, similarly to motivation [29], develop satisfaction due to improved learning outcomes and positive feedback, despite initial rejection stemming from potential cuts in usability. However, one needs to clarify whether satisfaction and impressions of usability may change in the long run.

The remarks regarding the quiz and the feedback functionalities of Backstage suggest that the effects of ARSs on active participation also apply to Backstage. To sum up, we may conclude that the users get along well with Backstage, even with the first (yet unfinished) prototypical implementation. No fundamental criticism was given, but further functionalities encouraged, e.g. the integration of presentation slides in Backstage. For the next stage of development we seized on this suggestion. The integration of presentation slides, however, needed careful consideration to fit the design rationale behind Backstage. This will be reported on in a companion paper in the near future.

\section{B. Questions}

Comparing the experimental to the control group, we could find indications for positive effects on the activity of the participants when using Backstage. Thus, more questions were raised on Backstage than being asked by the control group. The same applies to feedback addressed to the presenter. It should be noted that the participants of the control group only asked questions after invitation, maybe to avoid interrupting the presenter. In how far the increase of questions on Backstage has impact on the learning results needs to be investigated in a further study. However, we may assume that an increase of activity positively influences learning success and, therefore, motivation (e.g. [30]). However, as being stated by the participants, the raising of more questions may also contribute to distraction. Further investigation of this issue is required.

Regarding questioning, the findings of [25] could be confirmed. In the experimental group the majority of questions were factual questions, lesser were comprehension questions, and the least integration questions. We consider this outcome as an indication that questioning on Backstage needs guidance. In a further step in Backstage's development we thus reconsidered the interactions and the way they need to be made feasible in order to account for the need of guidance. This issue will also be presented in a forthcoming companion paper.

The high number of integration questions of the control group neither confirms the findings of [25], nor does it meet our expectations. However, this can be explained by the following two circumstances: (1) each remark in the smaller control group (compared to the experimental group) is in average of a greater influence (compared to the experimental group). (2) In the control group, most participants, i.e. three out of five, were students of Psychology and Educational Sciences and about to finish their studies. Since integration questions highly depend on prior knowledge, the described constellation of the group could explain the unexpected outcome. We cannot rule out that the topics chosen for the presentation have impinged on the participants' quality of questioning.

In summary, the findings of this preliminary study suggest that Backstage has positive influence on the activation of learners during presentations. Another aspect of active participation that deserves investigation, besides the support in asking questions, is the use of Backstage in large lecture classes. Participants noted the risk of distraction when using Backstage in a real lecture setting. Findings on the basis of the Cognitive Load Theory support the participants' appraisal [31]. If predominant distraction can be verified in forthcoming studies, then it is necessary to adapt lectures appropriately in order to leverage Backstage. For example, this can be achieved by conceding breaks for questioning on the backchannel. A more thorough structuring of the lecture by means of macro-scripts [32] may additionally support the versatile use of Backstage. In using these macro-scripts we can also include additional activities like collaboration in the lecture and support them in various ways.

\section{ENHANCING BACKSTAGE BY INTEGRATING PRESENTATION SLIDES}

According to the outcomes of the user study, we considered the most promising enhancement to be the integration of presentation slides in Backstage. Though being marginal at a first glance, this enhancement facilitates a great variety of improvements on the user interactions regarding both usability and educational aspects. It allows for consequent structuring of interactions on Backstage in a top-down fashion. The careful integration of slides into Backstage not only accounts for the importance of guidance of students but also improves comprehensibility and reduces distraction. The integration of slides is furthermore accompanied by re-adjustments of the interaction concept when necessary. This section is in parts based on [33] in which the interaction concept for Backstage is discussed particularly in the light of guidance.

\section{A. The integration of presentation slides}

From an educational point of view it is considered conducive for learning to relate the backchannel communication to some shared artifact [34]. As a first step towards such contextualization the backchannel discourse is displayed on the dashboard together with the presentation slides on a single screen (Figure 3 ). Since the integration of slides needs considerable amount of space a rework of the user interface is necessary.

Navigation in the slides can be realized in several ways. Thus, we may consider the students to navigate independently. From an educational point of view, though, independent navigation might be problematic, since it might lead to asynchronicity between the front- and the backchannel. Students may not proceed at the same pace as the lecturer, and thus may cope with topics currently not focused on in the frontchannel. A solution would be to let the lecturer decide which slide is currently displayed on the students' dashboards. However, this centralistic navigation approach might introduce interferences (e.g. race conditions) with the student's interactions, and could be perceived to be disturbing. 
For these reasons, and because we consider working with Backstage to replace taking handwritten notes by a student (cf. Subsection C), independent navigation in the slides is favored and currently employed. This may simplify adoption by students and reduce distraction stemming from the mere introduction of a new tool into the learning setting. In a traditional lecture a student may take handwritten notes for a random slide at her own pace. Thus, at least to some extent, asynchronicity is already part of traditional lectures. Replacing taking notes with working on Backstage does not introduce a new quality of asynchronicity.

However, other kinds of navigation might prove useful. Thus, different kinds of slide navigation, including the centralistic approach, can be used on Backstage.

\section{B. Reworking the Communication on Backstage to account for Slides}

The categorization of microblog messages mentioned above is a further means to relate the backchannel to the frontchannel discourse. In the tested prototype the assignment of messages to categories was optional which, however, bears several disadvantages. First, the aggregation of the backchannel by the lecturer relies on the student's willingness to categorize her messages. If many messages are left uncategorized, no meaningful overview can be given to the lecturer. Second, optional categorization of messages may lead a student to think that also messages not covered by the given categories, and off-topic messages in particular, may be posted. For these reasons categorizing messages is mandatory in the reworked concept of Backstage ${ }^{5}$. That is, before writing a message the student has to choose an appropriate category (shown in Figure 3).

Messages are always assigned to a distinct slide. This makes possible to filter out messages not belonging to the currently displayed slide. In a sense, by navigating in the slides, one also navigates in the backchannel discourse. The messages are furthermore related to specific locations on that slide they belong to which allows for a subdivision of a slide's backchannel discourse into threads. A thread can either be created or extended by a message, depending on whether a thread has been selected prior to sending the message. If a thread is selected the placement of an icon is omitted and the message is assigned to that thread. Otherwise, the message opens a new thread and has to be placed on the currently displayed slide in order to finish the composition process. In essence, relating a message to a certain location on a slide structures the entire backchannel discourse in a top-down fashion, which simplifies re-orientation after some time of absence and drastically improves comprehensibility of the backchannel discourse, since it accounts for, and retains, the inherent non-linear nature of chat communication [35].

The particular location at a slide is supposed to provide contextual meaning for the message. Thus, students can find out whether a message is of interest by the mere location, without the need to read the message. The proper referencing and the categorization of messages underlie social control exercised by the audience: badly

\footnotetext{
${ }^{5}$ Off-topic messages can still be supported by providing a respective category. The difference is that categorization makes the sort of communication desired more tangible and also simplifies social regulation by the audience.
}

categorized messages can be rated as irrelevant or offtopic, ill-located messages might not gain the desired attention and thus lack valuable responds. Thus, a student is encouraged to reference and to categorize her messages properly.

\section{Incentives for Students to Partake}

As mentioned above, communicating on Backstage may replace taking handwritten notes. On the basis of the backchannel discourse students may compile their own lecture notes in accordance with their needs. Additionally to a student's reputation that is determined on the basis of her posts' ratings, students may be encouraged to actively participate in the backchannel and to contribute valuable content. This functionality might also render economically marked motivation, e.g. by advertising extra credit points, redundant. The reuse of backchannel communication for further learning, e.g. exam preparations, is a per se justification for participation in the backchannel. It conveys to the student that not only the collaboration on Backstage but also the collaboration outcomes can be of great value for learning. Hence, interacting on Backstage does not end in itself.

Although not yet implemented, Backstage is thus planned to be enhanced by a follow-up dashboard that is used by students to rework a lecture. The follow-up dashboard allows a student to traverse the communication and select messages of interest, among other things. The compilation of individual lecture notes can be further supported by recommendation of messages on the basis of rating, or on the basis of the student's learning profile and performance, or a mixture of both. Besides, taking over a message to a student's lecture notes can be considered as an implicit rating, and thus may not only influence the quality of the message but also the reputation of the corresponding author.

\section{Reworking the Quiz Functionality of Backstage}

The integration of slides makes necessary to rework the conduct of quizzes on Backstage. During a quiz students should not be able to navigate in the presentation slides, nor should they be able to communicate. Hence, Backstage is operated in two modes, the backchannel and the quiz mode. Switching between the two modes of operation by starting or stopping a quiz allows the reuse of space at the dashboards, thereby retaining both the basic structure and the purposes of the dashboard parts. The display of slides, essentially being the passive element providing for he shared artifact, is replaced by the display of the quiz question. The microblog editor, being the active element of the dashboard is replaced by an input view used by a student to send a quiz reply (Figure 4). Retaining the purposes of the dashboard elements provides a seamless integration of the two operation modes for the user. Furthermore, the concept of input views accounts for types of quizzes with more complex replies and interactions.

The outcomes of a conducted quiz may also be valuable for students when reworking a lecture. Thus, the lecturer can decide to publish the results to the students' dashboards. That is, the quiz and its outcomes are transformed into slides and inserted into the existing presentation slides. Being ordinary slides, students can review the quiz at any time and engage in further backchannel interchange upon the outcomes as usual. 

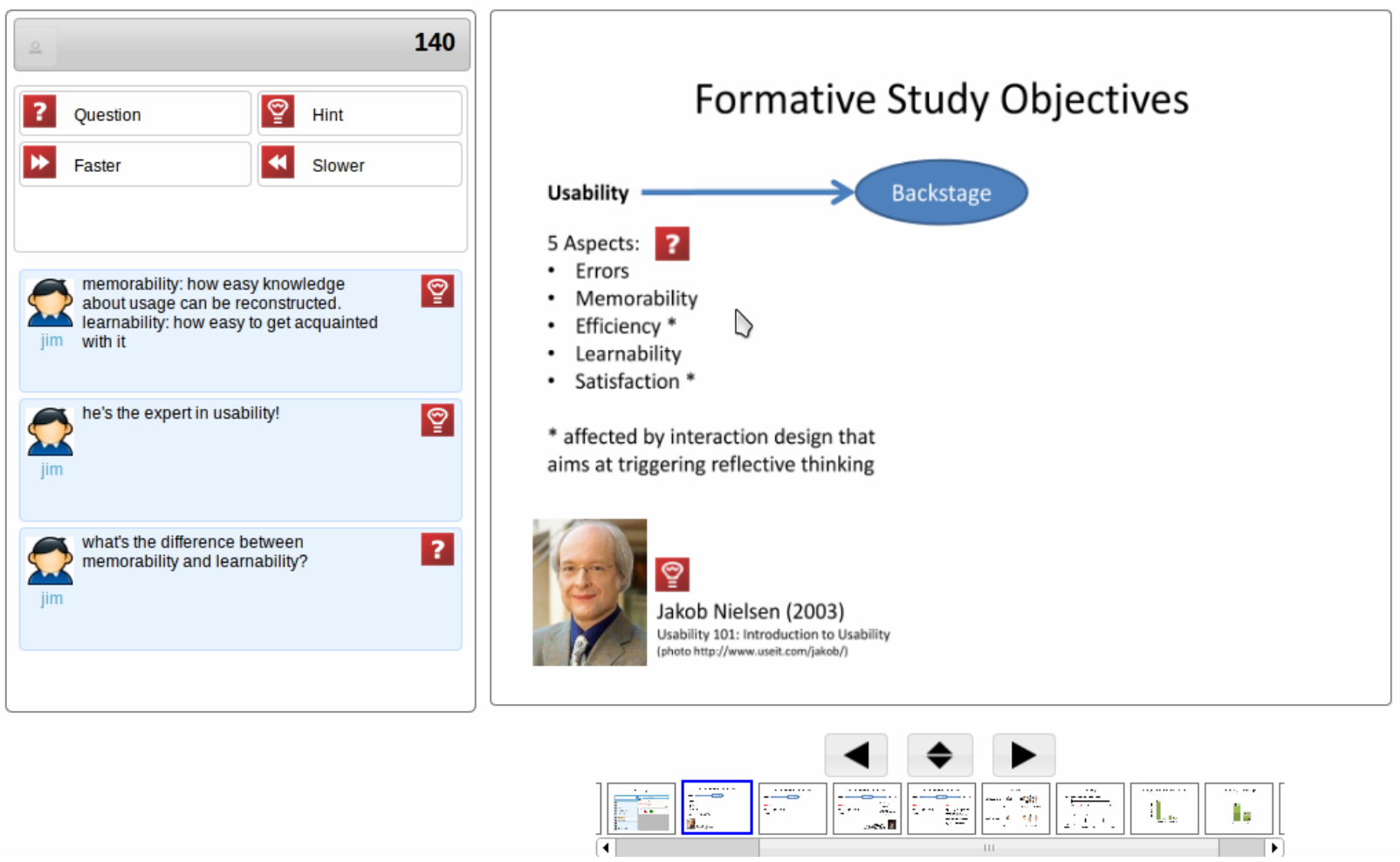

Figure 3. The left side of the student's dashboard shows the microblog window. To write a message the student first has to choose an appropriate category (top left). After selecting a category, the message itself is entered (not shown). The composition of messages is finished by placing an icon showing the message's category to a meaningful location of the slide that is displayed on the right side of the dashboard. The navigation is shown below the slides.

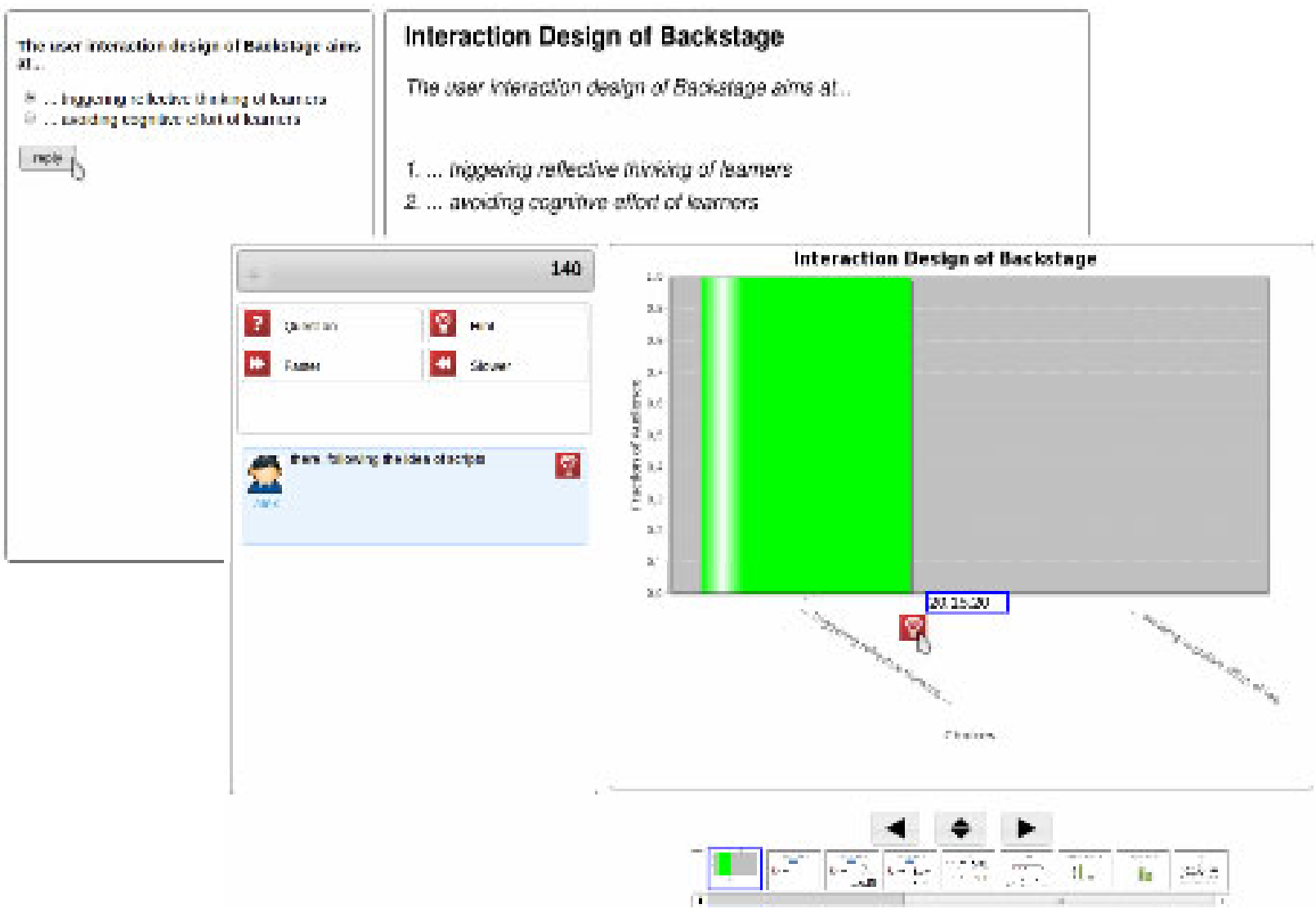

Figure 4. The picture in the back shows the student's dashboard during the conduct of quizzes. The microblog window is replaced by an input view for the quiz. The slides are replaced by the display of the quiz. The picture in the front shows the quiz result that is published by the lecturer. Hence, students can review and assign messages to the published results as usual 


\section{REFERENCES}

[1] R.E. Slavin, "Research on Cooperative Learning and Achievement: What We Know, What We Need to Know.," Contemporary Educational Psychology, vol. 21, 1996, pp. 43-69. http://dx.doi.org/10.1006/ceps.1996.0004

[2] A. Renkl, "Träges Wissen: Wenn Erlerntes nicht genutzt wird [Inert Knowledge: When what is learned is not used]," Psychologische Rundschau, vol. 47, 1996, pp. 78-92.

[3] H. Nassaji and G. Wells, "What's the Use of 'Triadic Dialogue'?: An Investigation of Teacher-Student Interaction," Applied Linguistics, vol. 21, 2000, pp. 376-406. http://dx.doi.org/10.1093 /applin/21.3.376

[4] G. Mietzel, Pädagogische Psychologie des Lehrens and Lernens [Educational Psychology of Teaching and Learning], Göttingen: Hogrefe, 2003.

[5] B. Rogoff, "Developing understanding of the idea of communities of learners," Mind, Culture, and Activity, vol. 1, 1994, pp. 209229.

[6] S.C. Herring, "Computer-Mediated Discourse," Handbook of Discourse Analysis, D. Tannen, D. Schiffrin, and H. Hamilton, eds., Oxford: Blackwell, in press.

[7] O.R. Kelm, "The Use of Synchronous Computer Networks in Second Language Instruction: A Preliminary Report," Foreign Language Annals, vol. 25, 1992, pp. 441-454. http://dx.doi.org/ 10.1111/j.1944-9720.1992.tb01127.x

[8] F. Bry, V. Gehlen-Baum, and A. Pohl, "Promoting Awareness and Participation in Large Class Lectures: The Digital Backchannel Backstage," Proceedings of the IADIS International Conference esociety, Spain, Avila: 2011, pp. 27-34.

[9] A. Pohl, V. Gehlen-Baum, and F. Bry, "Introducing Backstage -A Digital Backchannel for Large Class Lectures," Interactive Techology and Smart Education, vol. 8, 2011, p. in press.

[10] R.H. Kay and A. LeSage, "Examining the Benefits and Challenges of using Audience Response Systems: A Review of the Literature," Computers \& Education, vol. 53, 2009, pp. 819 - 827. http://dx.doi.org/10.1016/j.compedu.2009.05.001

[11] C. Fies and J. Marshall, "Classroom Response Systems: A Review of the Literature," Journal of Science Education and Technology, vol. 15, 2006, pp. 101-109. http://dx.doi.org/10.1007/s10956-006$\underline{0360-1}$

[12] R.W. Preszler, A. Dawe, C.B. Shuster, and M. Shuster, "Assessment of the Effects of Student Response Systems on Student Learning and Attitudes over a Broad Range of Biology Courses," CBE Life Science Education, vol. 6, 2007, pp. 29-41. http://dx.doi.org/10.1187/cbe.06-09-0190

[13] J. Cuseo, "The Empirical Case against Large Class Size: Adverse Effects on the Teaching, Learning, and Retention of First-Year Students," Journal of Faculty Development, vol. 21, 2007, pp. 521.

[14] J. Nielsen, "Usability 101: Introduction to Usability," 2003.

[15] K.A. Ericsson, "The Influence of Experience and Deliberate Practice on the Development of Superior Expert Performance," The Cambridge Handbook of Expertise and Expert Performance, K.A. Ericsson, N. Charness, P.J. Feltovich, and R.R. Hoffman, eds., Cambridge: Cambridge University Press, 2006, pp. 683-703.

[16] J. Piaget and R. Fatke, Meine Theorie der geistigen Entwicklung [My Theory about Intellectual Development], Beltz, 2003.

[17] L. Kobbe, A. Weinberger, P. Dillenbourg, A. Harrer, R. Hämäläinen, P. Häkkinen, and F. Fischer, "Specifying ComputerSupported Collaboration Scripts," International Journal of Computer-Supported Collaborative Learning, vol. 2, 2007, pp. 211-224. http://dx.doi.org/10.1007/s11412-007-9014-4

[18] I. Kollar, F. Fischer, and J.D. Slotta, "Internal and External Collaboration Scripts in Web-based Science Learning at Schools," Proceedings of the Conference on Computer Support for Collaborative Learning: Learning 2005: The Next 10 Years!, International Society of the Learning Sciences, 2005, pp. 331-340.

[19] A. Weinberger, F. Fischer, and K. Stegmann, "ComputerSupported Collaborative Learning in Higher Education: Scripts for Argumentative Knowledge Construction in Distributed Groups," Proceedings of the Conference on Computer Support for Collaborative Learning: Learning 2005: The Next 10 Years!, Taipei, Taiwan: International Society of the Learning Sciences, 2005, pp. 717-726.

[20] B. Ertl and H. Mandl, Kooperationsscripts als Lernstrategie [Cooperation Scripts as a Learning Strategy], München: 2004.
[21] B. Rosenshine and C. Meister, "Reciprocal Teaching: A Review of the Research.," Review of Educational Research, vol. 64, 1994, pp. 479-530.

[22] V. Aleven, E. Stahl, S. Schworm, F. Fischer, and R. Wallace, "Help Seeking and Help Design in Interactive Learning Environments," Review of Educational Research, vol. 73, 2003, pp. $277-320$. http://dx.doi.org/10.3102/00346543073003277

[23] A.S. Palinscar and A. Brown, "Reciprocal Teaching of Comprehension-Fostering and Comprehension-Monitoring Activities," Cognition and Instruction, vol. 1, 1984, pp. 117-175. http://dx.doi.org/10.1207/s1532690xci0102_1

[24] A. King, "Scripting Collaborative Learning Processes: A Cognitive Perspective," Scripting Computer-Supported Collaborative Learning, F. Fischer, I. Kollar, H. Mandl, and J.M. Haake, eds., Boston, MA: Springer US, 2007, pp. 13-37. http://dx.doi.org/10.1007/978-0-387-36949-5_2

[25] A. King, "Guiding Knowledge Construction in the Classroom: Effects of Teaching Children How To Question and How To Explain," American Educational Research Journal, vol. 31, 1994, pp. 358-68.

[26] D. Dansereau and A. O'Donnell, "Scripted Cooperation in Student Dyads: A Method for Analyzing and Enhancing Academic Learning and Performance.," Interactions in Cooperative Groups. The Theoretical Anatomy of Group Learning, New York: Cambridge University Press, 1992, pp. 120-141.

[27] L.J. Cronbach, "Coefficient Alpha and the Internal Structure of Tests," Psychometrika, vol. 16, 1951, pp. 297-334. http://dx.doi.org/10.1007/BF02310555

[28] J. Cohen, Statistical Power Analysis for the Behavioral Sciences, Routledge, 1988.

[29] E.L. Deci and R.M. Ryan, "The Support of Autonomy and the Control of Behavior," Journal of Personality and Social Psychology, vol. 53, 1987, pp. 1024-37. http://dx.doi.org/10.1037/ 0022-3514.53.6.1024

[30] E. Deci and R. Ryan, "Die Selbstbestimmungstheorie der Motivation und ihre Bedeutung für die Pädagogik [Self Theories on Motivation and their Implications for Pedagogy]," Zeitschrift für Pädagogik, vol. 2, 1993.

[31] J. Sweller, "Cognitive Load Theory, Learning Difficulty, and Instructional Design," Learning and Instruction, vol. 4, 1994, pp. 295-312. http://dx.doi.org/10.1016/0959-4752(94)90003-5

[32] P. Dillenbourg and P. Jermann, "Designing Integrative Scripts," Scripting Computer-Supported Collaborative Learning, F. Fischer, I. Kollar, H. Mandl, and J.M. Haake, eds., Boston, MA: Springer US, 2007, pp. 275-301. http://dx.doi.org/10.1007/978-0387-36949-5 16

[33] D. Baumgart, A. Pohl, V. Gehlen-Baum, and F. Bry, "Providing Guidance on Backstage, a Novel Digital Backchannel for Large Class Teaching," Education in a Technological World: Communicating Current and Emerging Research and Technological Efforts, Spain: Formatex, 2011, p. in press.

[34] D. Suthers and J. Xu, "Kükäkükä: An Online Environment for Artifact-Centered Discourse," Proceedings of the 11th World Wide Web Conference, 2002.

[35] T. Holmer, "Discourse Structure Analysis of Chat Communication,"Language@Internet, vol. 5, 2008.

\section{AUTHORS}

Alexander Pohl is with the Institute of Informatics at the University of Munich, Germany (e-mail: alexander.pohl@ifi.lmu.de).

Vera Gehlen-Baum is with the Department of Educational Technology at the Saarland University, Saarbrücken, Germany (e-mail: v.gehlen-baum@mx.unisaarland.de).

François Bry is with the Institute of Informatics at the University of Munich, Germany (e-mail: bry@lmu.de).

This article is an extended version of a paper presented at the International Conference ICL2011, held September 2011, in Piešt'any, Slovakia. Manuscript received 07 December 2011. Published as resubmitted by the authors 28 February 2012. 